\title{
Relative expression of rRNA transcripts and 45S rDNA promoter methylation status are dysregulated in tumors in comparison with matched-normal tissues in breast cancer
}

\author{
GURBET KARAHAN $^{1}$, NILUFER SAYAR ${ }^{1}$, GOKCEN GOZUM ${ }^{1}$, BETUL BOZKURT ${ }^{2}$, \\ OZLEN KONU ${ }^{1}$ and ISIK G. YULUG ${ }^{1}$
}

\author{
${ }^{1}$ Department of Molecular Biology and Genetics, Bilkent University, Faculty of Science, TR-06800 Ankara; \\ ${ }^{2}$ Department of General Surgery, Ankara Numune Research and Teaching Hospital, TR-06100 Ankara, Turkey
}

Received January 19, 2015; Accepted March 14, 2015

DOI: $10.3892 /$ or.2015.3940

\begin{abstract}
Ribosomal RNA (rRNA) expression, one of the most important factors regulating ribosome production, is primarily controlled by a CG-rich $45 \mathrm{~S}$ rDNA promoter. However, the DNA methylation state of the 45S rDNA promoter, as well as its effect on rRNA gene expression in types of human cancers is controversial. In the present study we analyzed the methylation status of the rDNA promoter ( -380 to $+53 \mathrm{bp}$ ) as well as associated rRNA expression levels in breast cancer cell lines and breast tumor-normal tissue pairs. We found that the aforementioned regulatory region was extensively methylated (74-96\%) in all cell lines and in 68\% (13/19 tumor-normal pairs) of the tumors. Expression levels of rRNA transcripts 18S, 28S, 5.8S and 45S external transcribed spacer (45S ETS) greatly varied in the breast cancer cell lines regardless of their methylation status. Analyses of rRNA transcript expression levels in the breast tumor and normal matched tissues showed no significant difference when normalized with TBP. On the other hand, using the geometric mean of the rRNA expression values (GM-rRNA) as reference enabled us to identify significant changes in the relative expression of rRNAs in the tissue samples. We propose GM-rRNA normalization as a novel strategy to analyze expression differences between rRNA transcripts. Accordingly, the $18 \mathrm{~S}$ rRNA/GM-rRNA ratio was significantly higher whereas the 5.8S rRNA/GM-rRNA ratio was significantly lower in breast tumor samples than
\end{abstract}

Correspondence to: Professor Isik G. Yulug, Department of Molecular Biology and Genetics, Bilkent University, Faculty of Science, TR-06800 Ankara, Turkey

E-mail: yulug@fen.bilkent.edu.tr

Abbreviations: rRNA, ribosomal RNA; rDNA, ribosomal DNA; GM-rRNA, geometric mean of rRNA expression values; 5-AZA, 5-aza-2'-deoxycytidine; TSA, trichostatin A

Key words: epigenetics, DNA methylation, ribosomal DNA, ribosomal RNA expression, breast cancer this ratio in the matched normal samples. Moreover, the $18 \mathrm{~S}$ rRNA/GM-rRNA ratio was negatively correlated with the $45 \mathrm{~S}$ rDNA promoter methylation level in the normal breast tissue samples, yet not in the breast tumors. Significant correlations observed between the expression levels of rRNA transcripts in the normal samples were lost in the tumor samples. We showed that the expression of rRNA transcripts may not be based solely on promoter methylation. Carcinogenesis may cause dysregulation of the correlation between spliced rRNA expression levels, possibly due to changes in rRNA processing, which requires further investigation.

\section{Introduction}

Breast cancer, the most common type of cancer among women, was also the primary and secondary cause of cancer-related deaths among women living in less developed (14.3\% of all cancer-related deaths) and more developed regions (15.4\% after lung cancer) in 2012, respectively (1). Familial or somatic mutations of BRCA1, BRCA2 and TP53 (alias p53) are wellknown high risk factors for breast cancer formation while others (PALB2, BRIP1, ATM, CHEK2, PTEN and CDH1) have been estimated to have moderate or weak effects (2).

Contrary to mutations that modify the DNA sequence itself, epigenetic alterations affect gene expression via DNA methylation, histone modifications and chromatin remodeling. DNA methylation, the frequently studied epigenetic modification in the context of embryogenesis, $\mathrm{X}$ chromosome inactivation and imprinting (3-5), is also important for the protection of genome integrity and hence cancer. Global hypomethylation of the genome, commonly observed in multiple cancers, increases genome instability and activates protooncogenes while hypermethylation of promoter $\mathrm{CpG}$ islands silences the expression of tumor suppressor genes (6-8). Promoter DNA methylation, identified at the promoter region of many genes, contributes to breast tumorigenesis; however, DNA methylation of the rDNA region has been overlooked in DNA methylation studies related to breast cancer.

Ribosome synthesis is closely related to the cell metabolism involved in cell growth and proliferation, and is tightly correlated with ribosomal RNA (rRNA) synthesis (9). The 
human genome contains $300-400$ copies of rRNA genes but only a fraction of these genes are actively transcribed depending on the cell type, external signals and the cell stage, while the rest of the genes remain inactive (10). rRNA genes are organized in tandem repeated arrays within nucleolar organizing regions (NORs) located on the short arms of five human acrocentric chromosomes: chromosome 13, 14, 15, 21 and 22 (11). rRNA genes (except 5S, which is transcribed by RNA polymerase III) are transcribed from the $45 \mathrm{~S}$ rDNA promoter by RNA polymerase I (Pol I). Since $\sim 60 \%$ of the total RNA of a cell consists of Pol I products (12), rRNA genes are regulated tightly at different levels that include pre-initiation complex (PIC) formation, initiation, promoter escape, elongation, termination, re-initiation, RNA processing and post-transcriptional modifications (13).

The entire promoter region of rRNA genes is contained in an intergenic spacer region (IGS) between rDNA units. The promoter region of rDNA repeating unit consists of two important elements: the core promoter and upstream control element (UCE). The core promoter is located between -50 to $+20 \mathrm{bp}$ and is essential for basal transcription, whereas the UCE is located 150-200 bp upstream of the transcription start site and is required for efficient pre-initiation complex formation (14) (Fig. 1A). Cooperative binding of the HMG1 box containing upstream binding factor (UBF) and the selectivity factor (SL1 or TIF-IB) to the promoter region is required for Pol I recruitment $(15,16)$. rRNA genes are transcribed as long precursors known as $45 \mathrm{~S}$ pre-RNA which are then rapidly spliced into the 18S, 28S and 5.8S rRNA transcripts (17). Processed and modified rRNA transcripts are assembled into respective ribosomal subunits in the nucleolus $(18,19)$.

The association between the nucleolus and cancer has long been known. Abnormal morphology of the nucleolus in cancer cells has drawn the attention of tumor pathologists since the 19th century. However, only recently has the molecular biology of rRNA synthesis and ribosome biogenesis in cancer cells begun to be explored.

$\mathrm{CpG}$ island methylation at the promoters of tumor suppressor genes is known to be an important factor in the formation and progression of many types of cancer (20). The promoter and transcribed regions of rRNA genes are rich in $\mathrm{CG}$ dinucleotide yet they are longer than regular 1 to $2 \mathrm{~kb} \mathrm{CpG}$ islands (21). A limited number of studies analyzing the DNA methylation status of the rDNA promoter region in cancer have focused on the relationship between rDNA promoter methylation and the expression levels of rRNA genes.

Methylation at the 45S rDNA promoter region decreased the expression of rRNA genes in hepatocellular carcinoma (22) and in $\mathrm{CD}^{3} 4^{+}$cells of patients with myelodysplastic syndromes (23). On the other hand, other studies have shown no relationship or a positive correlation between promoter methylation and rRNA transcription $(24,25)$.

Although rRNA genes and particularly 18S RNA are frequently used in qRT-PCR as housekeeping genes, recent studies have shown that $18 \mathrm{~S}$ is differentially expressed in breast tumor and normal samples (26-28). Furthermore, changes in the relative amount of spliced rRNA products from $45 \mathrm{~S}$ have not been tested in the context of breast cancer.

$\mathrm{CpG}$ methylation of rDNA has been identified as a prognostic factor in ovarian, endometrial and breast cancer (29-31).
A recent study also revealed that the $45 \mathrm{~S}$ rDNA promoter as well as the 5 ' regions of $18 \mathrm{~S}$ and $28 \mathrm{~S}$ rDNA are hypermethylated in breast cancer tissues compared to paired normal tissues. Notably, methylation levels of these regions exhibited a correlation with nuclear grade and nuclear size values (32). However, none of the previous breast cancer studies examined the ratio of rRNA transcript levels and rDNA promoter methylation levels in tumors and normal tissues comparatively.

In the present study, we analyzed the methylation levels of the 45S rDNA promoter in breast cancer cell lines as well as in primary breast tumor tissues and matched normal samples. We also determined the expression levels of rRNA transcripts in the same samples in order to understand the role of rDNA promoter methylation on rRNA gene expression in breast cancer. We showed for the first time that the relative expression ratio of $18 \mathrm{~S}$ and $5.8 \mathrm{~S}$ rRNA was differentially modulated in tumors in comparison to adjacent normal tissues. In addition, relative rRNA expression in normal tissues was significantly and negatively correlated with the methylation status but this was not observed in the breast tumors. Furthermore, the high correlation between expression of rRNA transcripts in normal breast tissue was lost in tumors. Our findings suggest a significant dysregulation of relative rRNA expression in conjunction with promoter methylation.

\section{Materials and methods}

Cell culture, 5-aza-2'-deoxycytidine (5-AZA) and trichostatin A (TSA) treatments. MCF7, MDA-MB-453, MDA-MB-468, BT20, MDA-MB-231 and CAMA-1 breast cancer cell lines were grown in $10 \%$ fetal bovine serum (FBS) (HyClone, Thermo Scientific, USA) and $1 \%$ penicillin/streptomycin (P/S) supplemented with low glucose Dulbecco's modified Eagle's medium (DMEM) (both from HyClone). ZR-75-1 cell line was grown in $10 \% \mathrm{FBS}, 1 \% \mathrm{P} / \mathrm{S}$ and $2 \mathrm{mM}$ glucose (Sigma-Aldrich, USA) supplemented with RPMI-1640 medium (HyClone). BT-474 cell line was propagated in $10 \% \mathrm{FBS}, 1 \% \mathrm{P} / \mathrm{S}$ and $10 \mu \mathrm{g} /$ $\mathrm{ml}$ insulin (Sigma-Aldrich) supplemented with low glucose DMEM. MDA-MB-157 and MDA-MB-361 cell lines were grown in $10 \%$ FBS, $1 \mathrm{mM}$ sodium pyruvate (Gibco, Invitrogen, USA) and $1 \% \mathrm{P} / \mathrm{S}$ supplemented with low glucose DMEM. HCC-1937 cell line was propagated in $10 \% \mathrm{FBS}, 1 \% \mathrm{P} / \mathrm{S}$ and $1 \mathrm{mM}$ sodium pyruvate supplemented with RPMI-1640 medium. MCF10A was grown in $10 \% \mathrm{FBS}, 1 \% \mathrm{P} / \mathrm{S}, 10 \mu \mathrm{g} / \mathrm{ml}$ insulin, $20 \mathrm{ng} / \mathrm{ml}$ EGF and $0.5 \mathrm{mg} / \mathrm{ml}$ hydrocortisone (both from SigmaAldrich) supplemented with DMEM/Ham's F-12 (1:1) medium (Biochrome, Merck Millipore, Germany). SKBR-3 cell line was grown in $10 \%$ FBS and 1\% P/S supplemented with McCoy's 5A medium (HyClone). CAL-51 cell line was propagated in $20 \%$ FBS and $1 \% \mathrm{P} / \mathrm{S}$ supplemented with high glucose medium. All cells were grown in $5 \% \mathrm{CO}_{2}$ and $95 \%$ air at $37^{\circ} \mathrm{C}$ in a cell culture incubator. All cell lines except MCF-10A and CAL-51 cells were purchased from the American Type Culture Collection (ATCC; Rockville, MD, USA). MCF-10A and CAL-51 were kindly provided by Assistant Professor Dr A. Elif Erson (Middle East Technical University). Short tandem repeat profiling was used to verify the authenticity of all cell lines.

A total of 10 breast cancer cell lines (MCF7, MDA-MB231, MDA-MB-453, MDA-MB-468, BT-474, ZR-75-1, BT-20, MDA-MD-361, SKBR-3 and CAL-51) and one non-tumor- 
igenic breast cell line (MCF-10A) were treated with 5-AZA or TSA. Cells seeded at a density of $750,000 / 100 \mathrm{~mm}$ were treated with either $5 \mu \mathrm{M}$ 5-AZA (Sigma-Aldrich) or dimethyl sulfoxide (DMSO) (same amount used to solubilize 5-AZA). Drugs were changed every day along with the medium, and cells were collected on day 5. $400 \mathrm{nM}$ TSA or DMSO (same amount used to solubilize TSA) was administered to the cells $24 \mathrm{~h}$ after cell plating, and the cells were collected after $48 \mathrm{~h}$.

A total of 10 cell lines (MCF7, MDA-MB-231, MDA-MB453, MDA-MB-468, BT-474, ZR-75-1, BT-20, SKBR-3, CAL-51 and MCF-10A) were treated with both 5-AZA and TSA (combination treatment). 5-AZA $(5 \mu \mathrm{M})$ was added at the day of seeding and $400 \mathrm{nM}$ TSA was added $72 \mathrm{~h}$ later in combination treatment (5-AZA+TSA); the cells were collected on day 5 .

Patients and tissue samples. Primary breast tumors and matched normal tissues were obtained from 19 patients at Ankara Numune Research and Teaching Hospital (Table I). Clinical tissue samples were used with the approval of the Research Ethics Committee of Ankara Numune Research and Teaching Hospital, and consent was obtained from the patients according to the Helsinki Declaration.

Tissues acquired from patients during surgery were immediately frozen with liquid nitrogen and stored at $-80^{\circ} \mathrm{C}$ until RNA or DNA extraction was performed. Pathological examinations were carried out with hematoxylin and eosin staining. Only the tumor samples identified by pathological examination consisting of $>80-90 \%$ tumor cells were included in the present study.

DNA extraction and bisulfite treatment. Genomic DNA was extracted from the breast cancer cell lines as well as the clinical breast cancer and matched normal tissue samples using the NucleoSpin Tissue DNA extraction kit (Macherey-Nagel, Germany) following the manufacturer's instructions.

Sodium bisulfite treatment of DNA, which converts unmethylated cytosine residues to uracil leaving methylated cytosine residues unaffected, was performed with $1 \mu \mathrm{g}$ genomic DNA using the EpiTect Bisulfite kit (Qiagen, Germany). Elution was performed using $20 \mu \mathrm{l}$ of elution buffer.

Bisulfite-specific PCR, gel extraction and bisulfite genomic sequencing. Bisulfite-converted DNA $(1 \mu \mathrm{l})$ was amplified with Taq DNA polymerase (Fermentas, Thermo Scientific, USA) using bisulfite DNA-specific primers (22) targeting the 45S rDNA promoter (45S bisulfite sequencing forward and reverse primer sequences are listed in Table II). PCR products were extracted from the gel using the QIAquick Gel Extraction kit (Qiagen). Purified products were cloned into the pGEM-T Easy Vector using the pGEM-T Easy Vector system (Promega, USA). The transformation protocol was performed according to the pGEM-T Easy Vector system manual using competent E. coli DH5 $\alpha$. Bacteria were plated on LB-agar containing ampicillin (AppliChem, Germany), IPTG and X-Gal (both from Fermentas) and positive clones (five colonies from cell lines and 10 colonies from tissue samples) were randomly selected.

Small-scale isolation of plasmid DNA (mini-prep) was performed with the NucleoSpin Plasmid Isolation kit
(Macherey-Nagel) according to the manufacturer's instructions. Plasmids containing the cloned inserts were confirmed with PCR using T7 and SP6 universal primers. The insertcontaining plasmids were sequenced with SP6 primers using the dideoxy chain-termination method (Iontek, Turkey).

Methylation analysis. Raw bisulfite sequencing data were analyzed using the QUantification tool for Methylation Analysis) (QUMA), a web-based quantification tool for methylation analysis (http://quma.cdb.riken.jp) (33). Bisulfite conversion rates of raw sequencing data were determined by analyzing unconverted cytosine residues in non-CG sites. Clones with a bisulfite conversion rate of $<95 \%$ were excluded. Clones from each sample were trimmed, aligned and displayed as lollipop graphs using QUMA.

RNA isolation and cDNA synthesis. The frozen tumor (4-5 slices for each sample) and normal (20-25 slices for each sample) tissue samples were cut into $60-\mu \mathrm{m}$ sections and used for RNA isolation. Tissue samples were lysed in $1 \mathrm{ml}$ TRI reagent RT (Molecular Research Center, USA) with a homogenizer and passed through a 21-gauge needle several times. After a 5-min incubation at room temperature, $50 \mu \mathrm{l}$ of 4-bromoanisole (Molecular Research Center) was added $/ \mathrm{ml}$ of TRI reagent. Tubes were vortexed for $15 \mathrm{sec}$ and incubated at room temperature for 2-3 $\mathrm{min}$. After incubation, the mixture was centrifuged at $12,000 \mathrm{x} \mathrm{g}$ for $15 \mathrm{~min}$ at $4^{\circ} \mathrm{C}$ and then the aqueous phase was collected into a clean tube. Isopropanol $(0.5 \mathrm{ml})$ was added to the aqueous phase $/ 1 \mathrm{ml}$ of TRI reagent used. The mixture was incubated at room temperature for $10 \mathrm{~min}$ and then centrifuged at $12,000 \mathrm{x}$ g for $15 \mathrm{~min}$ at $4^{\circ} \mathrm{C}$ to recover the RNA. The supernatant was removed, and the pellet was washed with $75 \%$ ethanol twice and centrifuged at 7,500 x g for $5 \mathrm{~min}$ at $4^{\circ} \mathrm{C}$. The pellet was air-dried and dissolved in diethylpyrocarbonate (DEPC)-treated $\mathrm{H}_{2} \mathrm{O}$. In order to avoid DNA contamination of the total RNA acquired from the tissue samples, DNase I treatment was performed with the Message Clean kit (GenHunter, USA) according to the manufacturer's instructions. Total RNA (500 ng) was used in random primed cDNA synthesis with the RevertAid First Strand cDNA Synthesis kit (Fermentas).

RNA isolation from the cell lines was performed using the NucleoSpin RNA II RNA isolation kit (Macharey-Nagel) following the manufacturer's protocol. Total RNA $(1 \mu \mathrm{g})$ was used in random primed cDNA synthesis with the RevertAid First Strand cDNA Synthesis kit.

Real-time PCR. Real-time PCR was performed with primers targeting 45S ETS, 18S, $28 \mathrm{~S}$ and 5.8 rRNA transcripts. All primer sequences are listed in Table II. Randomly primed cDNAs from both cell lines and frozen tissue samples were diluted in a $1 / 5$ ratio. Diluted cDNA $(1 \mu \mathrm{l})$ was used in every reaction containing $10 \mu \mathrm{l}$ of DyNAmo SYBR-Green qPCR kit (Thermo Scientific) and 10 pmol of forward and reverse primers in a final volume of $20 \mu \mathrm{l}$. Thermal cycling conditions were as follows: initial denaturation for $5 \mathrm{~min}$ at $95^{\circ} \mathrm{C}$, 40 cycles of $30 \mathrm{sec}$ at $95^{\circ} \mathrm{C}, 30 \mathrm{sec}$ at $60^{\circ} \mathrm{C}$ and $30 \mathrm{sec}$ at $72^{\circ} \mathrm{C}$ followed by melting curve. All reactions were set as duplicates. The Stratagene Mx3005P Real-Time PCR System (Agilent, USA) was used for real-time PCR experiments. 


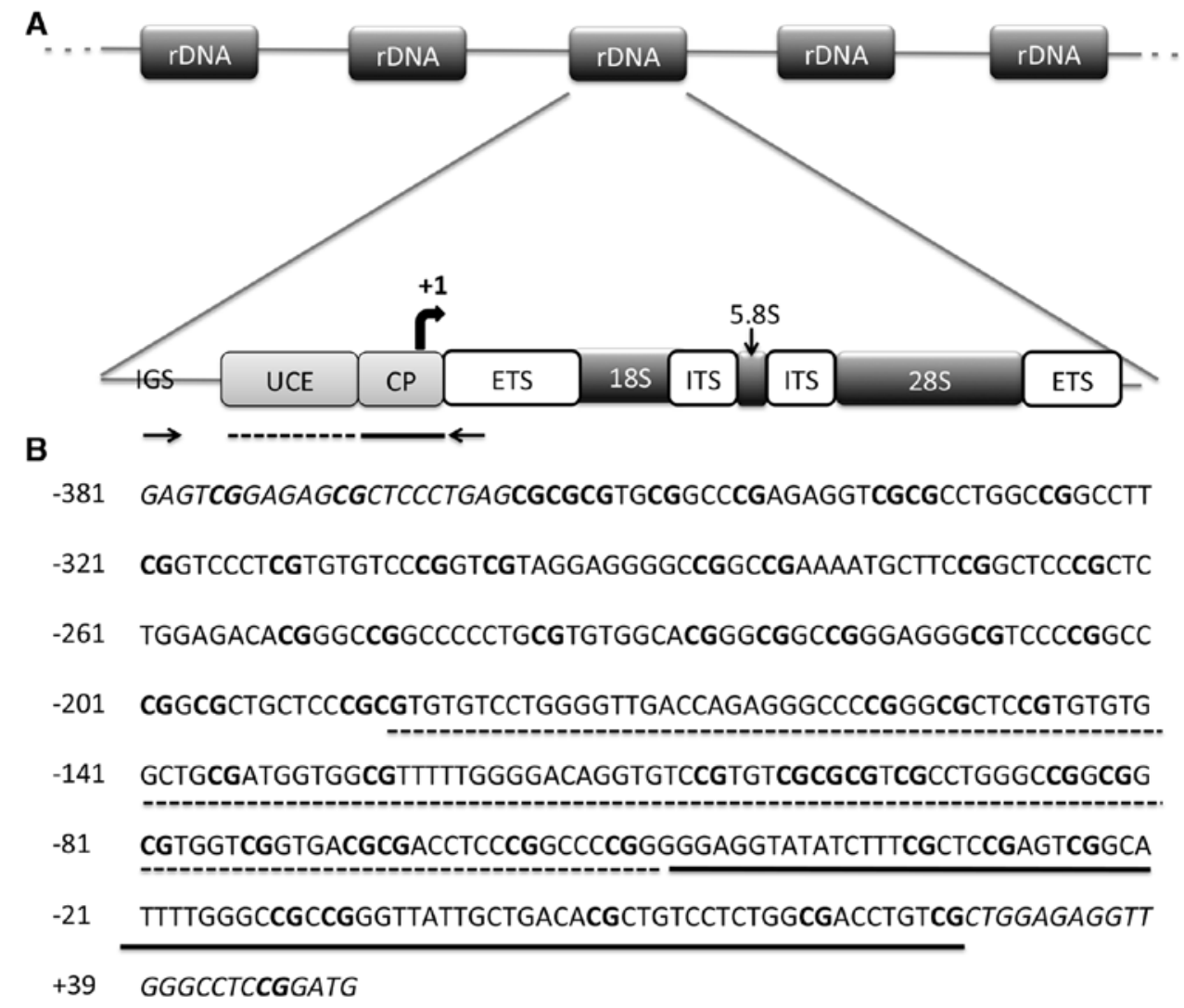

Figure 1. The human rDNA promoter. (A) Structural organization of human rDNA repeating unit. Bisulfite sequencing primers are shown by inward pointing arrows. IGS, intergenic spacer; UCE, upstream control element; CP, core promoter; ETS, external transcribed spacer; ITS, internal transcribed spacer. (B) Sequence of the amplified PCR product, spanning the upstream core element (marked with dashed line) and the core promoter (straight line). There are $54 \mathrm{CpGs}$ in the 434-bp region analyzed; the transcription start site is indicated with a curved arrow. Primers are shown with italicized characters and CG-dinucleotides are indicated with bold characters. rDNA, ribosomal DNA.

The relative expression levels of rRNAs were evaluated using $\log 2\left(2^{\Delta \mathrm{Cr}}\right)$ calculation. TBP was used as the reference gene both for cell lines and clinical tissue samples to assess the amount of cDNA. The geometric mean of the rRNA expression values (GM-rRNAs) (18S, 28S, 5.8S and 45S ETS) was also used as a reference gene in tissue samples in order to understand the relative changes of rRNAs with respect to each other.

Statistical analysis. Raw bisulfite sequencing data were aligned, trimmed and quality checked using QUMA. Lollipop graphs and pie charts of the methylation status were also generated using QUMA (33). The Wilcoxon matched pairs signed rank test was used to assess both sample-wise and CpG-wise significant methylation differences between breast tumor and matched normal samples. Significant expression differences were determined using the paired t-test. Correlations between 45S rDNA promoter methylation and rRNA expression levels, as well as rRNA transcripts with each other were analyzed using Spearman correlation.

The association of rDNA promoter methylation and rRNA expression with clinical variables was evaluated with Spearman correlation. $\mathrm{p}<0.05$ was accepted as statistically significant for all statistical analyses. All statistical analyses of methylation and expression data were performed using IBM SPSS software version 21.0 or GraphPad Prism 6.0.

\section{Results}

45S rDNA promoter is highly methylated in breast cancer cell lines. To identify the methylation levels of the 45S rDNA promoter region in breast cancer in vitro, we performed bisulfite genomic sequencing for the 45S rDNA promoter region in 10 breast cancer cell lines and a non-tumorigenic breast cell line (MCF-10A). Bisulfite sequencing primers were obtained from a previous study (22), which amplified a 434-bp region spanning two important elements: UCE and the core promoter (34) (Fig. 1B). Isolated DNAs from the cell lines were treated with sodium bisulfite reagent, allowing for integration of epigenetic information (DNA methylation) into genetic information. Five randomly selected clones from each cell line were sequenced, aligned and analyzed using QUMA (33). All cell lines, including a non-tumorigenic breast cell line, MCF-10A, exhibited very high levels of methylation (varying between 74 and 96\%) in their 45S rDNA promoter regions (Fig. 2).

Breast tumors are heavily methylated compared to their normal matched tissues in the $45 S$ rDNA promoter region. We analyzed 19 breast tumor and matched normal frozen tissues (Table I) using the same bisulfite genomic sequencing method to test whether methylation levels of the 45S rDNA promoter region in patient samples were similar to those of the cell lines. Ten randomly selected clones were sequenced, 
Table I. Clinicopathological characteristics of the patients.

\begin{tabular}{|c|c|c|c|c|c|c|c|c|c|}
\hline $\begin{array}{l}\text { Patient } \\
\text { no. }\end{array}$ & $\begin{array}{c}\text { Age } \\
\text { (years) }\end{array}$ & ER & PR & Diagnosis & $\begin{array}{c}\text { Path } \\
\text { lymph node }\end{array}$ & Grade & $\begin{array}{l}\text { Clinical } \\
\text { grade }\end{array}$ & DM & $\begin{array}{l}\text {-DM } \\
\text { month }\end{array}$ \\
\hline 113 & 63 & + & - & IDC & + & 1 & Grade 3B & + & 20 \\
\hline 115 & 57 & & & Papillary carcinoma & - & 3 & Grade $2 \mathrm{~A}$ & - & \\
\hline 96 & 39 & - & + & IDC & - & 2 & Grade $2 \mathrm{~A}$ & - & \\
\hline 116 & 74 & - & - & IDC & + & 2 & Grade $2 \mathrm{~A}$ & - & \\
\hline 137 & 42 & - & + & Medullary & - & 3 & Grade 2B & - & \\
\hline 146 & 49 & + & + & ILC & + & & Grade 2B & - & \\
\hline 148 & 70 & + & - & IDC & + & 2 & Grade 3A & + & 15 \\
\hline 154 & 32 & - & - & IDC & + & 3 & Grade 3B & - & \\
\hline 159 & 30 & - & + & Metaplastic & - & 2 & Grade $2 \mathrm{~A}$ & - & \\
\hline 161 & 41 & - & - & IDC & - & 2 & Grade 2B & + & 47 \\
\hline 164 & 74 & + & + & IDC & - & 2 & Grade 2B & - & \\
\hline 166 & 55 & - & + & IDC & + & 2 & Grade $2 \mathrm{~A}$ & - & \\
\hline 168 & 44 & - & + & IDC & + & 2 & Grade 2B & - & \\
\hline 170 & 60 & - & - & IDC & + & 2 & Grade 3B & - & \\
\hline 176 & 49 & + & + & IDC & + & 2 & Grade 2A & - & \\
\hline 177 & 47 & - & + & IDC & + & 2 & Grade 3A & + & 48 \\
\hline 181 & 44 & - & - & IDC & + & 2 & Grade 1 & - & \\
\hline \multicolumn{10}{|l|}{$133^{\mathrm{a}}$} \\
\hline $173^{\mathrm{a}}$ & & & & & & & & & \\
\hline
\end{tabular}

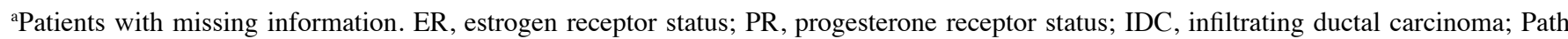
lymph node, pathological lymph node status; DM, distant metastasis status.

Table II. Primers used in the present study.

\begin{tabular}{|c|c|c|c|c|}
\hline Primer & & Sequence & $\begin{array}{l}\text { Product size } \\
\text { (bp) }\end{array}$ & $\begin{array}{c}\text { Efficiency } \\
\text { value }\end{array}$ \\
\hline $45 \mathrm{~S}$ bisulfite sequencing primers & Forward & 5'-GAGTCGGAGAGCGCTCCCTGAG-3' & 434 & - \\
\hline $45 \mathrm{~S}$ bisulfite sequencing primers & Reverse & 5'-CTGGAGAGGTTGGGCCTCCG-3' & & \\
\hline $18 \mathrm{~S}$ rRNA & Forward & 5'-AAACGGCTACCACATCCAAG-3' & 154 & 1.95 \\
\hline 18S rRNA & Reverse & 5'-CCTCCAATGGATCCTCGTTA-3' & & \\
\hline 28S rRNA & Forward & 5'-CAGGGGAATCCGACTGTTTA-3' & 151 & 1.85 \\
\hline 28SS rRNA & Reverse & 5'-ATGACGAGGCATTTGGCTAC-3' & & \\
\hline 5.8S rRNA & Forward & 5'-CTCTTAGCGGTGGATCACTC-3' & 155 & 2.00 \\
\hline 5.8S rRNA & Reverse & 5'-GACGCTCAGACAGGCGTAG-3' & & \\
\hline 45S ETS & Forward & 5'-CGATCTGAGAGGCGTGCCTT-3' & 87 & 1.93 \\
\hline 45S ETS & Reverse & 5'-GGCAGCGCTACCATAACGGA-3' & & \\
\hline TBP & Forward & 5'-TGCACAGGAGCCAAGAGTGAAAT-3' & 134 & 2.20 \\
\hline TBP & Reverse & 5'-CACATCACAGCTCCCCACCA-3' & & \\
\hline
\end{tabular}

rRNA, ribosomal RNA; ETS, external transcribed spacer.

aligned and analyzed from each of the breast tumor and normal pairs using QUMA (33). We used the Wilcoxon signed rank test for testing the paired differences instead of the Mann-Whitney U test offered by the QUMA tool. Our results revealed that 13 out of $19(68 \%)$ breast cancer tissue samples had higher methylation levels of the $45 \mathrm{~S}$ rDNA. On the other hand, three samples showed significantly higher methylation levels in normal samples compared to their tumor pairs, whereas there was no significant difference between promoter methylation levels in breast tumor and matched normal tissues 


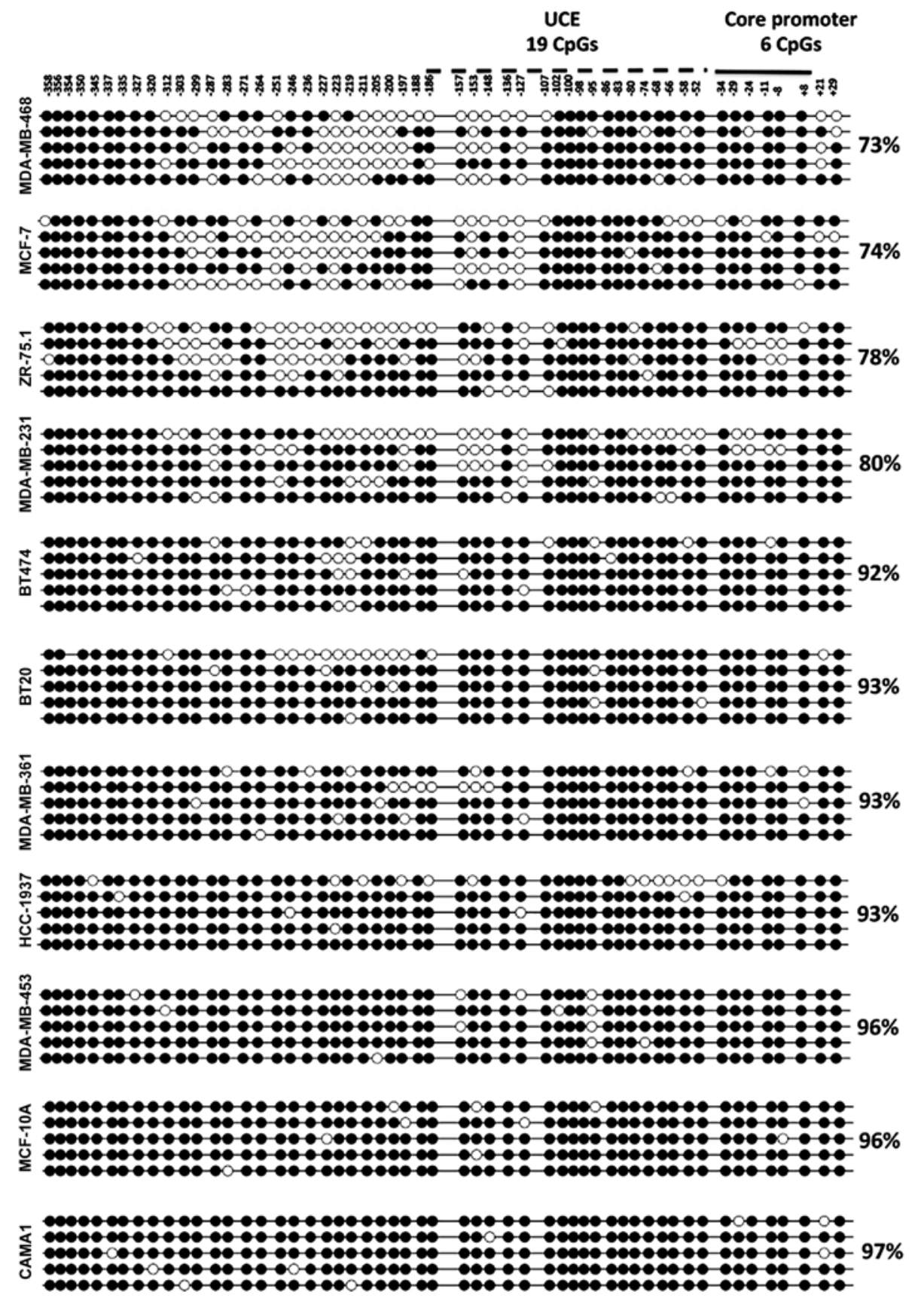

Figure 2. The methylation status of the $45 \mathrm{~S}$ rDNA promoter in breast cancer cell lines and a non-tumorigenic cell line. A total of $54 \mathrm{CpGs}$ in a region spanning -381 to +53 bp was analyzed by the bisulfite sequencing method. Each row corresponds to the sequence analysis of one clone and each column represents the $\mathrm{CpG}$ positions. The filled and empty circles stand for methylated and unmethylated $\mathrm{CpGs}$, respectively. Average methylation percentages of the clones for each sample are indicated at the right of the graph. UCE, upstream control element.

in the remaining three samples (Fig. 3A). Normal samples were not fully unmethylated and instead showed a mosaic methylation pattern, a relatively common observation for human rDNA promoters (22). Methylation patterns of tumor and normal pairs showed a significant correlation with each other. To test whether this correlation was due to patient-specific methylation of rDNA promoters, we performed a correlation analysis between randomly selected tumor and normal samples; and these showed similar degrees of correlation (data not shown). In addition, the analysis of individual CpGs in tumor and normal pairs revealed significant methylation levels in different $\mathrm{CpGs}$ identified with the Wilcoxon matched pairs signed rank test (Fig. 3B).
No significant correlation was identified between rDNA promoter methylation levels and patient clinical variables.

Expression levels of rRNA transcripts in breast cancer. TBP, GAPDH and ACTB have been used as reference genes to determine rRNA expression levels in several studies $(23,24,35)$ but these RNA polymerase II (Pol II) transcribed genes are variably expressed in numerous types of cancer $(36,37)$. However, several studies advise against using rRNA levels to determine mRNA levels $(26,27)$. Accordingly, using mRNA levels to normalize rRNA levels may have a similar drawback. Herein, we propose that GM-rRNA, the geometric mean of expression from an rRNA pool (18S, 28S, 5.8S and 45S ETS) 


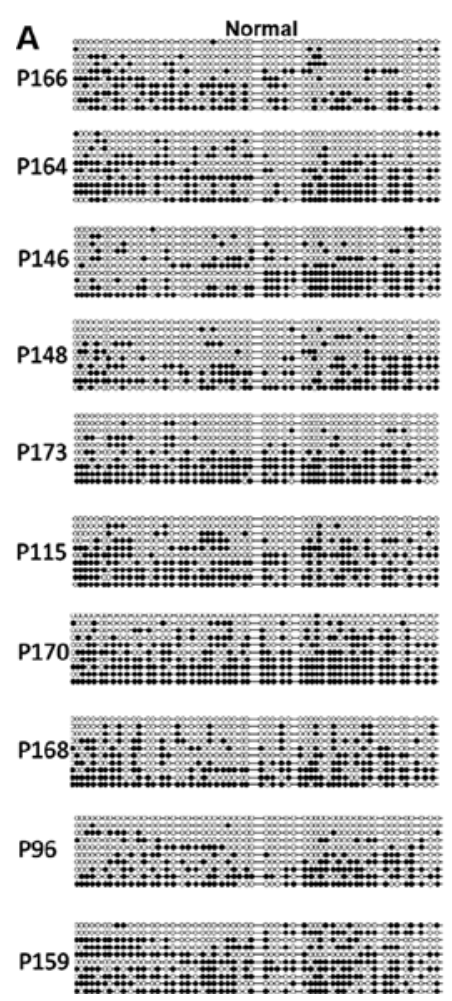

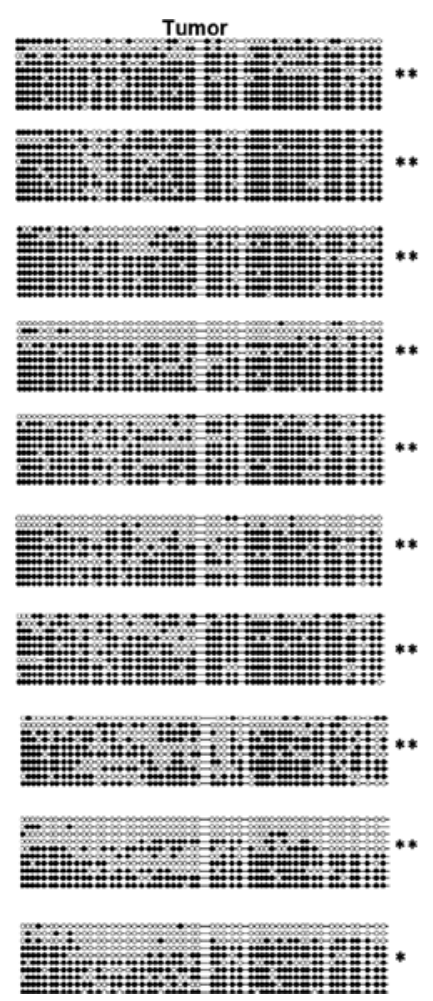
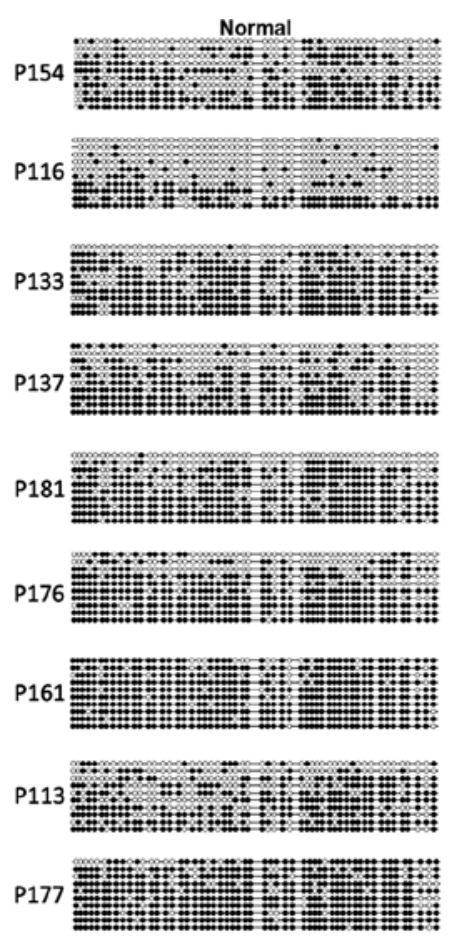
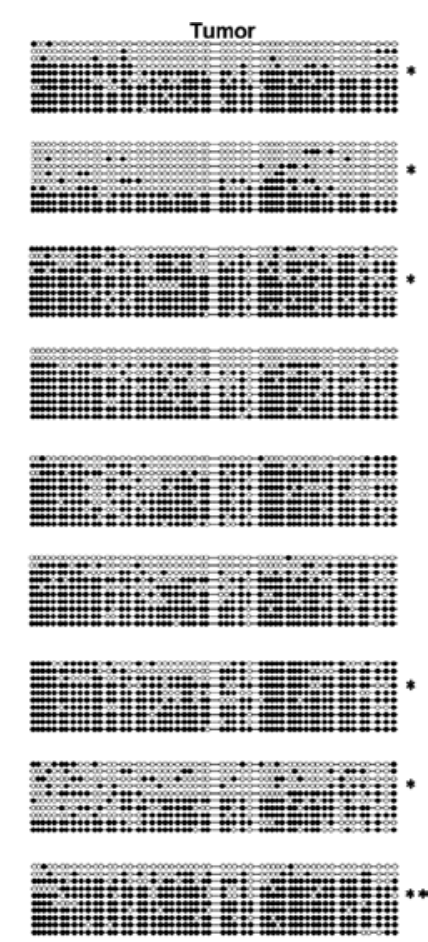

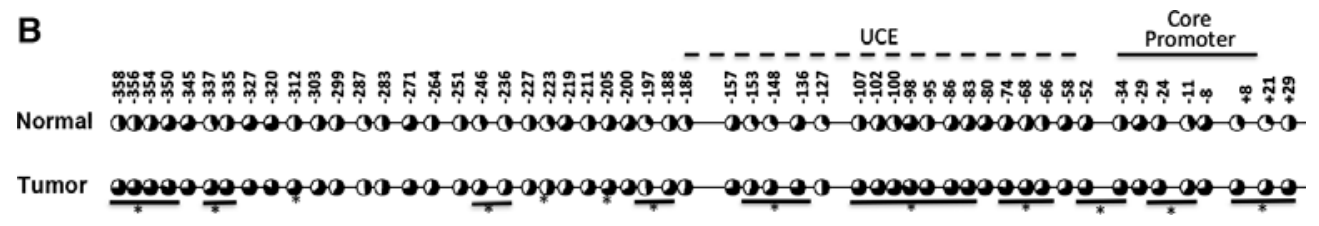

Figure 3. Methylation status of the 45S rDNA promoter region in clinical breast cancer and matched normal tissues. (A) The methylation status of each CpG dinucleotide in the region spanning -381 to +53 bp was analyzed in 19 breast cancer and normal pairs. Ten randomly selected clones were sequenced from each sample. Significant $\left(* \mathrm{*}<0.0001\right.$ and $\left.{ }^{*} \mathrm{p}<0.05\right)$ methylation difference between tumor and matched normal samples. (B) Methylation levels of every $\mathrm{CpG}$ in all tumor clones and normal clones were compared to determine differentially methylated CpGs. Methylation percentages of every $\mathrm{CpG}$ are presented as a pie chart. Significantly $\left({ }^{*} \mathrm{p}<0.05\right)$ methylated $\mathrm{CpGs}$ in tumor samples compared to normal samples.
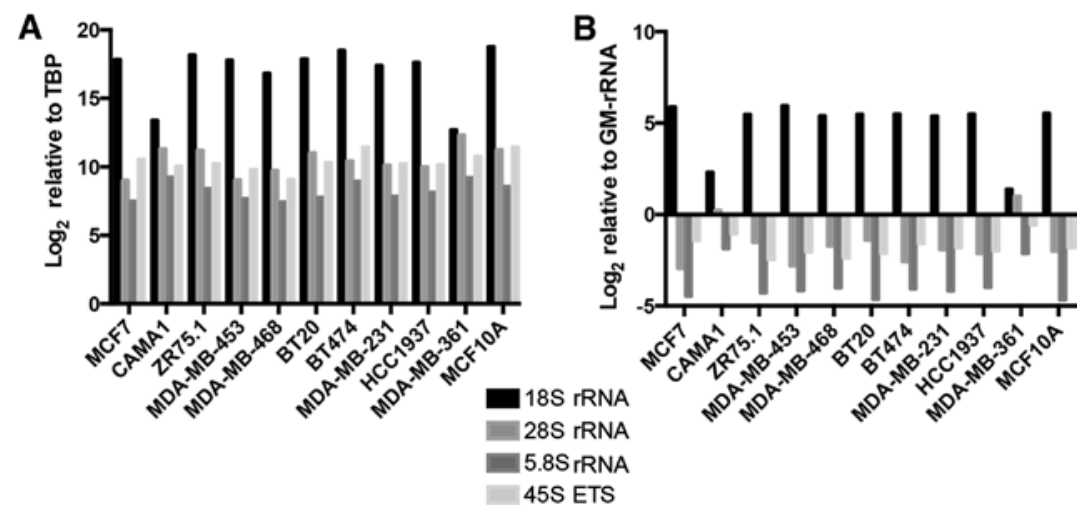

Figure 4. rRNA transcript levels in breast cancer cell lines (A) Relative expression levels of rRNA transcripts in the breast cancer cell line panel, normalized to the TBP transcript level. (B) Relative proportions of rRNA transcripts in the breast cancer cell line panel, normalized to GM-rRNA.

synthesized by Pol I, can be used to analyze relative changes in rRNAs with respect to each other between tumor and normal samples, as well as in cell lines. We performed our analyses using both TBP and GM-rRNA normalization to test the effect of normalization on expression changes in rRNA transcripts.

Expression of rRNA transcripts is highly variable in breast cancer cell lines. It is known that promoter DNA methylation has a repressive effect, particularly on Pol II transcribed genes in cancer $(20,38)$ and increased methylation levels are implicated in decreased levels of rRNA transcription $(22,23)$. Thus, we hypothesized that rRNA transcription levels may also be downregulated in these breast cancer cell lines with a hypermethylated 45S rDNA promoter. Total RNA was isolated and tested in cell lines with qRT-PCR using primers targeting 

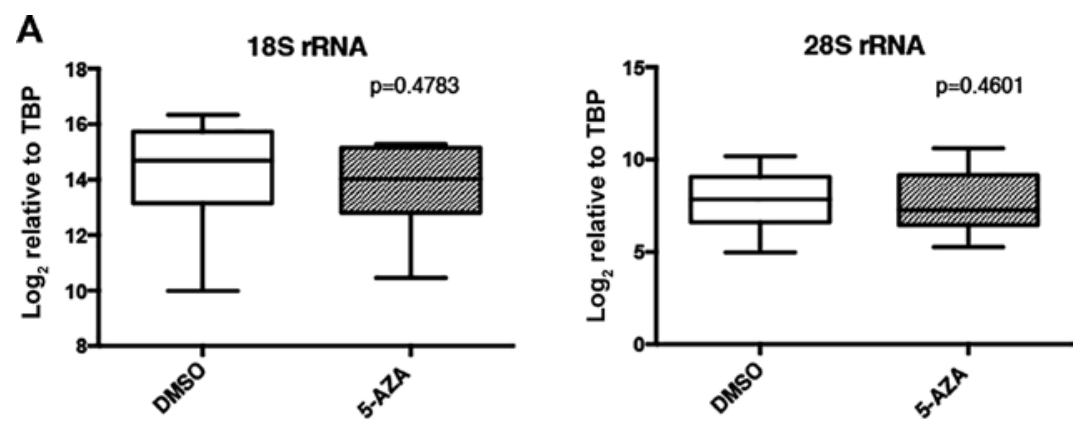

5.8S rRNA

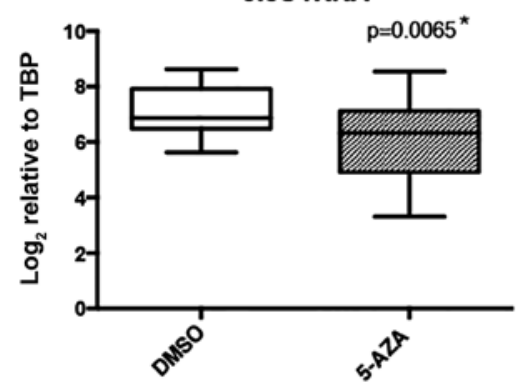

45S ETS
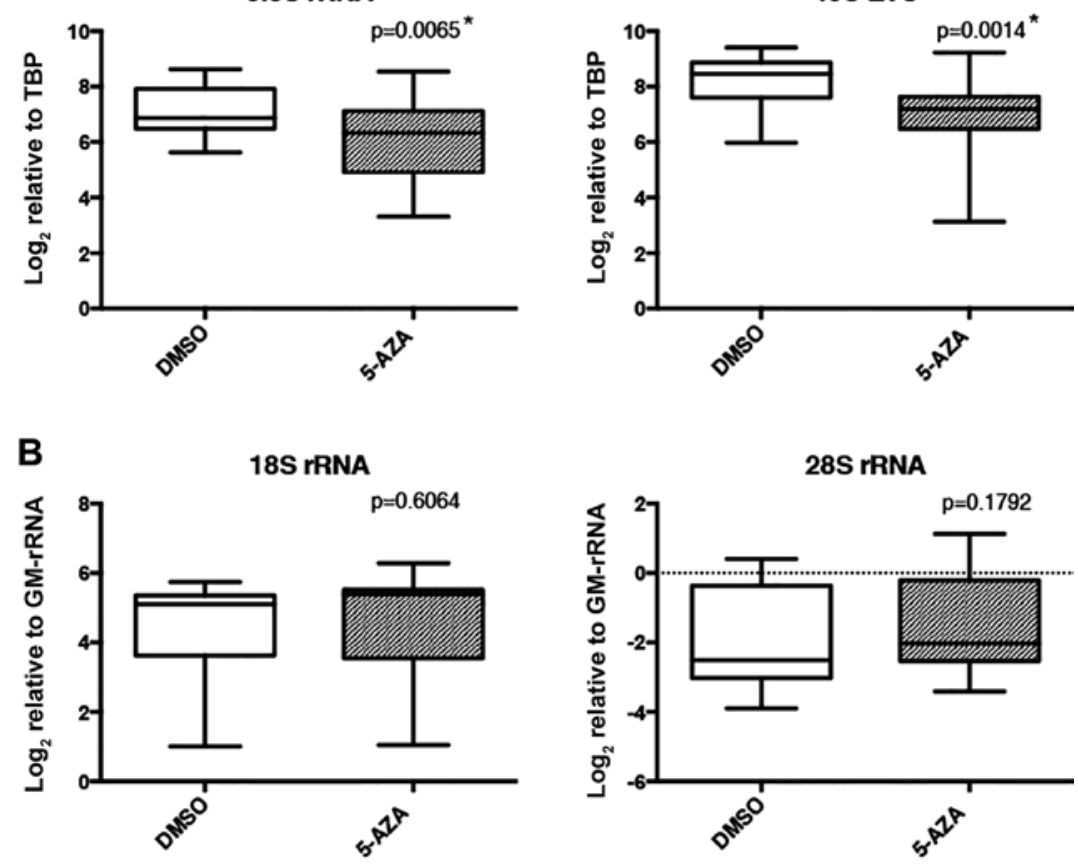

5.8S rRNA
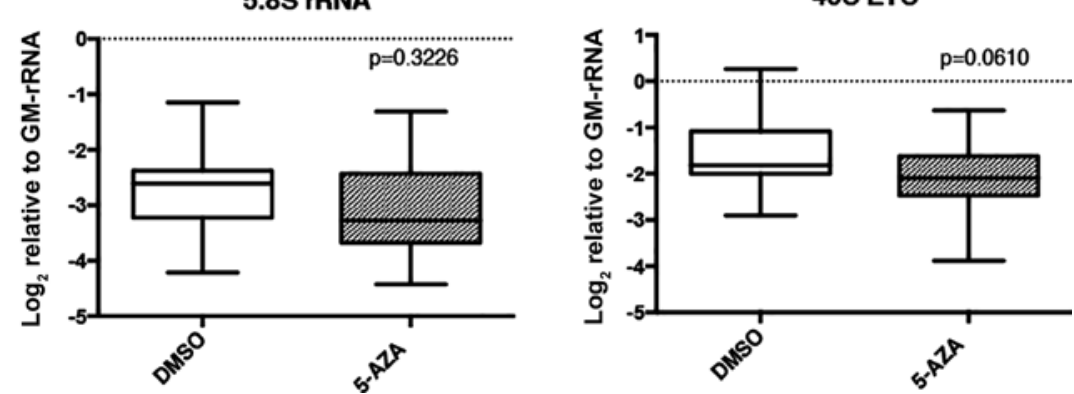

Figure 5. rRNA transcript levels in 5-AZA- and DMSO (control)-treated cell lines. (A) Expression levels of rRNA transcripts in 5-AZA- or DMSO-treated breast cell lines. Expression levels of rRNA transcripts were normalized to the TBP transcript level. (B) Relative proportions of rRNA transcripts in the 5-AZA- or DMSO-treated breast cell lines. Expression levels of rRNA transcripts were normalized to GM-rRNA. Box plots indicate relative expression levels of rRNA transcripts in the DMSO- and 5-AZA-treated cell lines. Significant ( $\left.{ }^{*} \mathrm{p}<0.05\right)$ rRNA expression differences between DMSO- and 5-AZA-treated cell lines were determined using the paired t-test. rRNA, ribosomal RNA; 5-AZA, 5-aza-2'-deoxycytidine; DMSO, dimethyl sulfoxide; GM-rRNA, geometric mean of rRNA expression values.

Pol I products $18 \mathrm{~S}, 28 \mathrm{~S}, 5.8 \mathrm{~S}$ and $45 \mathrm{~S}$ external transcribed spacer (ETS) region.

All of the rRNA transcripts were expressed at varying levels among the cell lines when normalization was performed with the TBP gene (Fig. 4A). Similar results were obtained when we used GM-rRNA to determine changes in the ratio of the rRNA transcripts (Fig. 4B).

Epigenetic drugs 5-AZA and 5-AZA+TSA modulate expression of rRNA transcripts. To further establish the relationship between $45 \mathrm{~S}$ rDNA promoter methylation and
rRNA expression, we used the hypomethylating agent, 5-AZA, which prevents DNA methylation by inhibiting DNA methyltransferases (39) and leads to increased RNA transcription. TBP normalized expression levels of 5.8S and 45S ETS transcripts were significantly decreased upon 5-AZA treatment (Fig. 5A). However, proportion of rRNA transcripts did not exhibit significant differences between 5-AZA- and DMSO-treated samples (normalization with GM-rRNA) (Fig. 5B).

TSA is a non-specific histone deacetylase (HDAC) inhibitor. TSA treatment of cells affects the acetylation status of 
A

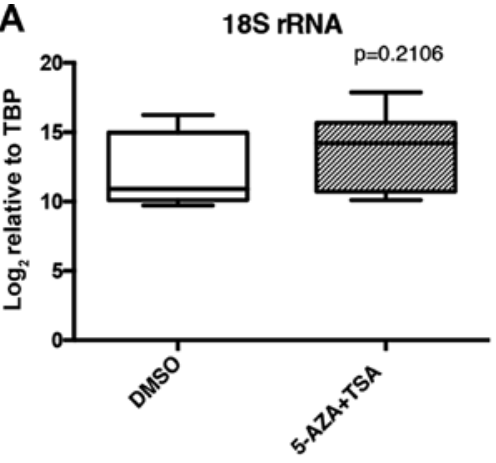

5.8S rRNA

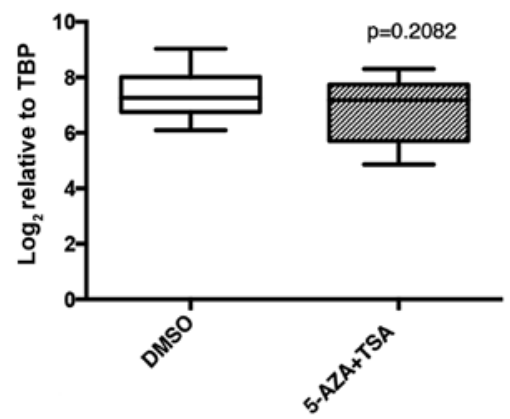

B

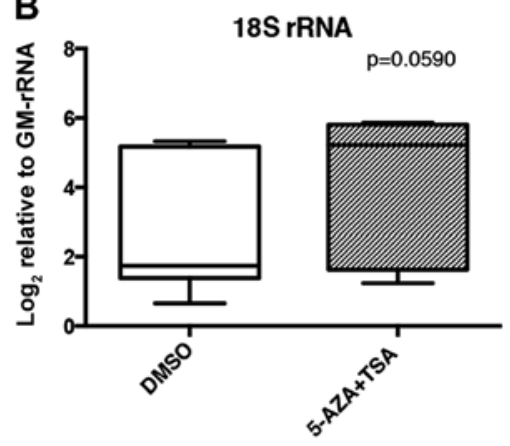

5.8S rRNA

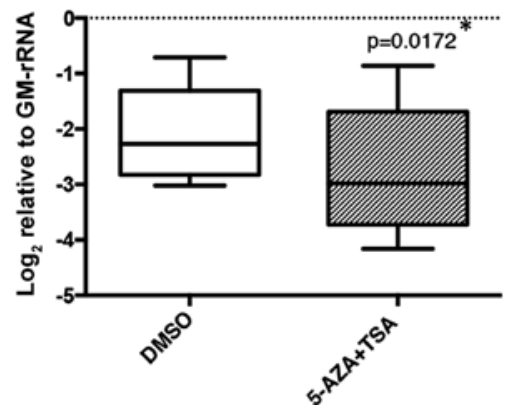

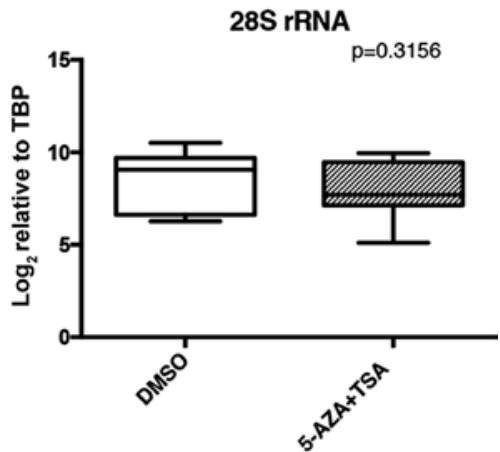

45S ETS

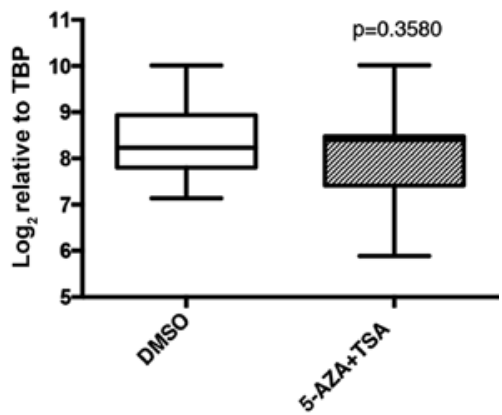

28S rRNA

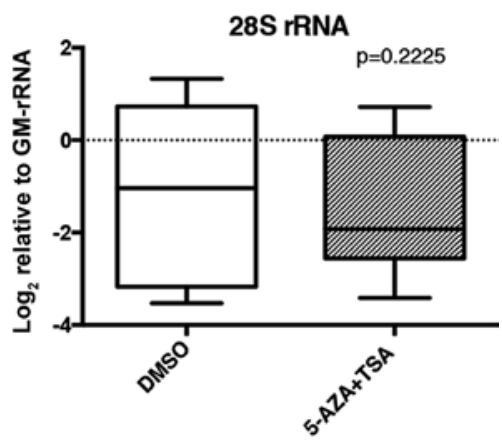

45S ETS

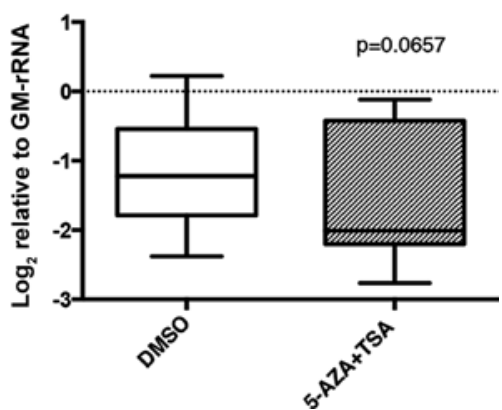

Figure 6. rRNA transcript levels in the 5-AZA+TSA- and DMSO (control)-treated cell lines. (A) Expression levels of rRNA transcripts in the 5-AZA+TSAor DMSO-treated breast cell lines. Expression levels of rRNA transcripts were normalized to the TBP transcript level. (B) Relative proportions of rRNA transcripts in the 5-AZA+TSA- or DMSO-treated breast cell lines. Expression levels of rRNA transcripts were normalized to GM-rRNA. Box plots indicate relative expression levels of rRNA transcripts in the DMSO- and 5-AZA+TSA-treated cell lines. Significant ( ${ }^{*}$ p<0.05) rRNA expression differences between DMSO- and 5-AZA+TSA-treated cell lines were determined using the paired t-test. rRNA, ribosomal RNA; 5-AZA, 5-aza-2'-deoxycytidine; TSA, trichostatin A; DMSO, dimethyl sulfoxide; GM-rRNA, geometric mean of the rRNA expression values.

$\mathrm{H} 3$ and $\mathrm{H} 4$ and thus TSA indirectly upregulates gene expression by dispersion of the chromatin structure (39). Therefore, TSA was used to determine whether other mechanisms (such as histone acetylation) are involved in the rRNA synthesis besides DNA methylation. TSA treatment alone did not significantly alter the expression levels or the relative proportions of the rRNA transcripts when normalized with TBP or GM-rRNA, respectively (data not shown). Treatment with
5-AZA and TSA together (5-AZA+TSA) did not significantly affect the TBP normalized expression levels of the rRNA transcripts (Fig. 6A). However, the 5.8S proportion of rRNAs was significantly decreased in the 5-AZA+TSA-treated samples compared to the DMSO-treated samples (Fig. 6B).

Relative expression levels of 185 and 5.85 transcripts are altered in breast tumors. Next, we tested whether increased levels of methylation of the $45 \mathrm{~S}$ rDNA promoter in tumor 

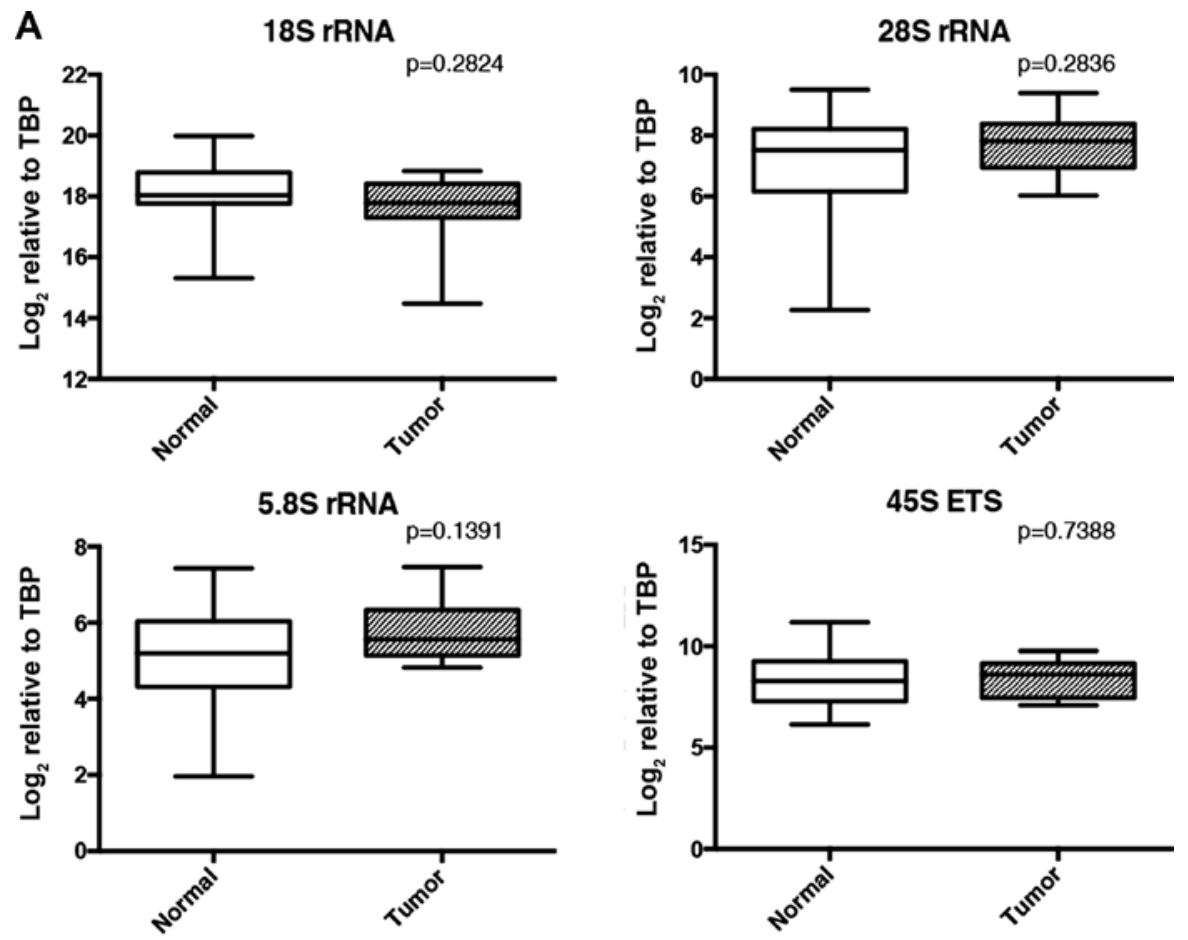

45S ETS
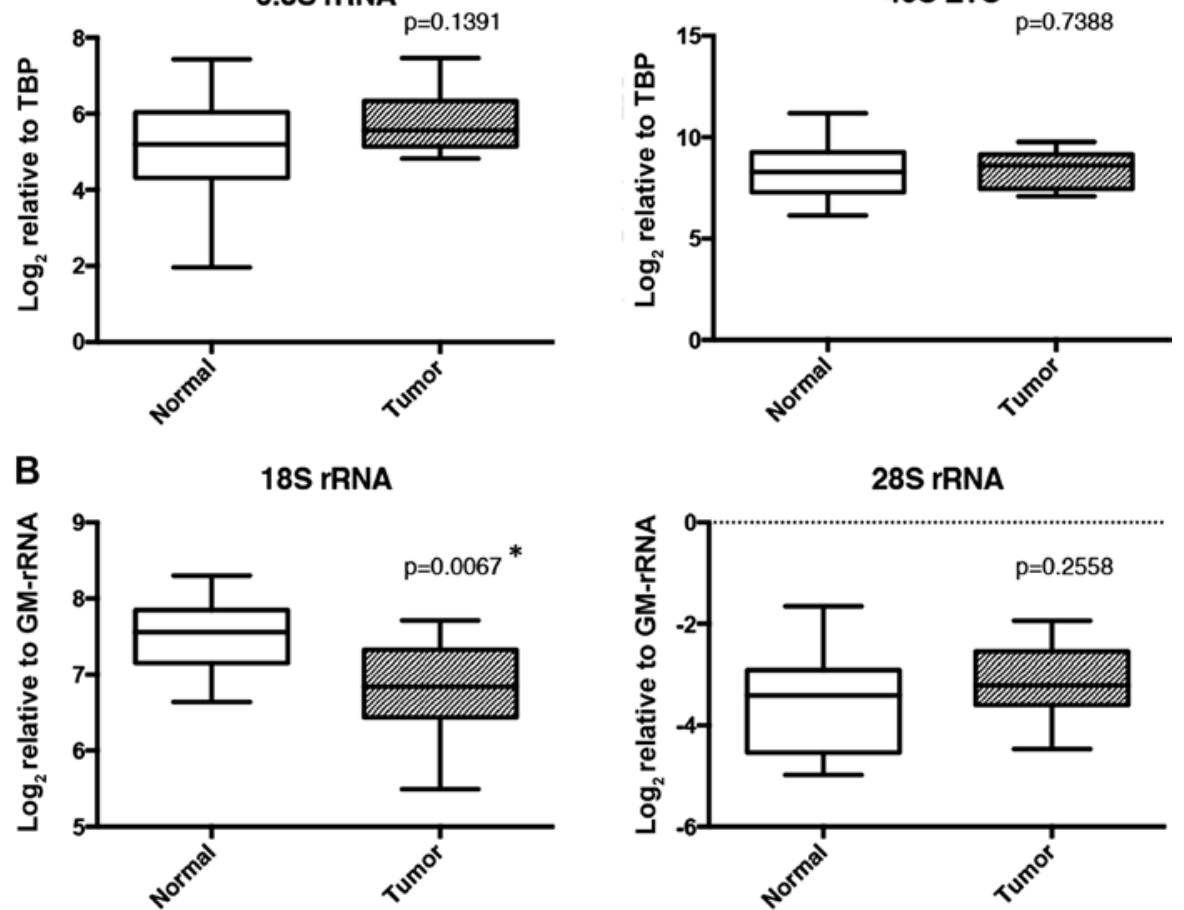

5.8S rRNA
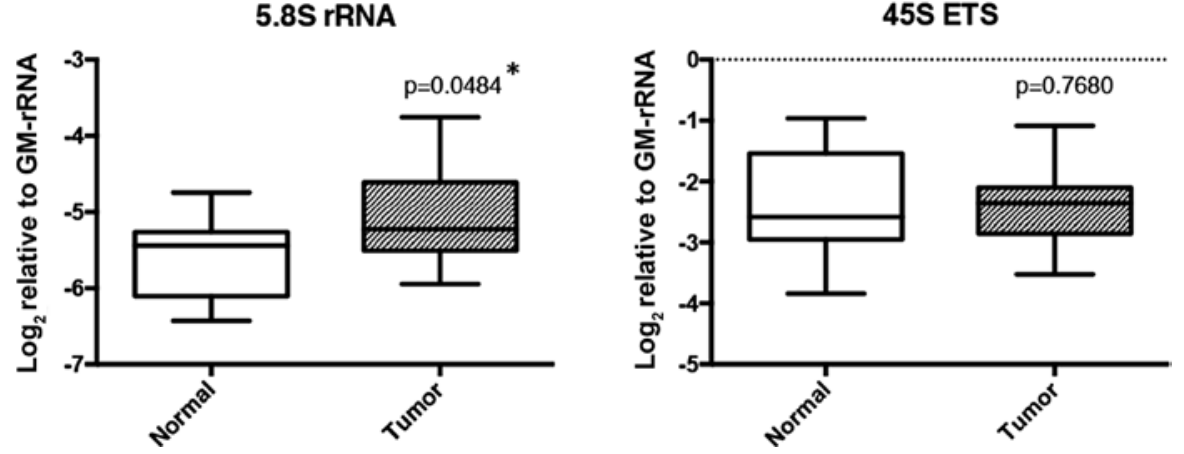

Figure 7. Expression analysis of rRNA transcripts in clinical breast cancer and normal pairs. Relative expression levels of rRNA transcripts are shown with box plots for the clinical breast cancer and matched normal samples. (A) Expression levels of rRNA transcripts were normalized to the TBP transcript level. (B) Expression levels of rRNA transcripts were normalized to GM-rRNA. Significant ( $\left.{ }^{\mathrm{p}}<0.05\right)$ expression differences between normal and tumor samples were determined using paired t-test. rRNA, ribosomal RNA; GM-rRNA, geometric mean of the rRNA expression values.

samples led to repressed expression levels of rRNA transcripts. RNA isolation was performed from the same tissue samples used in the methylation analysis (only 14 of 19 paired tissue samples had enough tissue for RNA isolation). Expression levels, when analyzed using TBP as a reference gene, did not differ between the tumors and corresponding adjacent normal tissues for any of the rRNA transcripts (Fig. 7A). However, when normalized with GM-rRNA, the proportion of $18 \mathrm{~S}$ was significantly decreased in the tumor samples whereas that of 5.8S rRNA was significantly increased (Fig. 7B).

rRNA transcripts are expressed independent from $45 S$ rDNA promoter methylation levels in breast cancer cell lines. There was no significant correlation of rDNA methylation levels with rRNA expression levels or rRNA ratios in the breast cancer cell lines or in the MCF10A cells (non-tumorigenic cell line). 

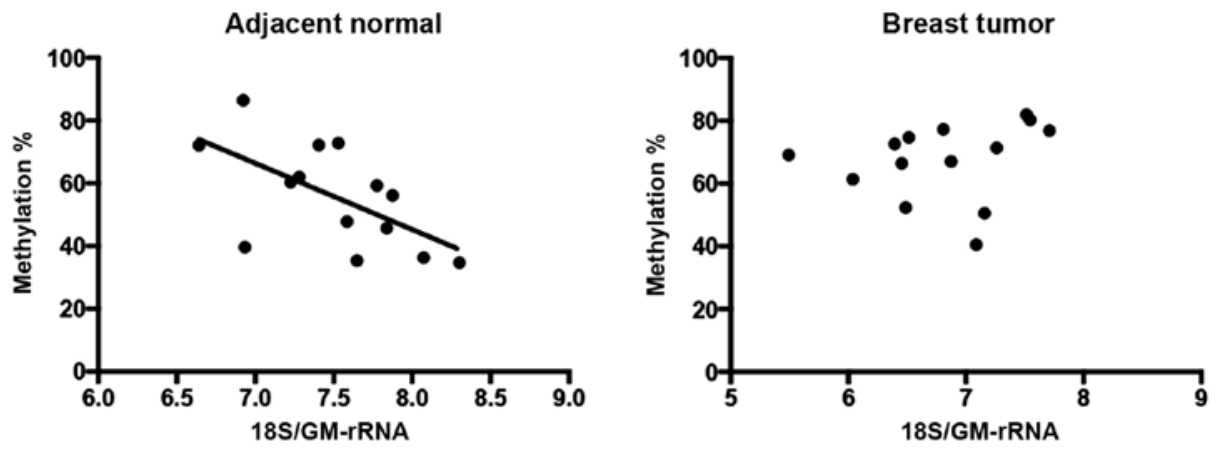

\begin{tabular}{lll}
\hline Spearman $\mathrm{r}$ & $-\mathbf{0 . 6 5 7 1 ^ { \star }}$ & 0.3934 \\
\hline Spearman $\mathrm{p}$ & $\mathbf{0 . 0 1 2 8}$ & 0.1652 \\
\hline
\end{tabular}

Figure 8. Correlation graph of 45S rDNA promoter methylation levels and 18S rRNA ratios in breast tumor and matched normal tissue samples. A significant correlation $\left({ }^{*} \mathrm{p}<0.05\right)$ was identified using Spearman correlation analysis.

Table III. Correlation analysis between rRNA transcripts in tumor and normal samples.

\begin{tabular}{llccc}
\hline Sample & Transcript & 28S rRNA & $5.8 \mathrm{~S}$ rRNA & 45S ETS \\
\hline Normal & 18S rRNA & $0.837(\mathrm{p}<0.01)^{\mathrm{a}}$ & $0.824(\mathrm{p}<0.01)^{\mathrm{a}}$ & $0.818(\mathrm{p}<0.01)^{\mathrm{a}}$ \\
& 28S rRNA & & $0.833(\mathrm{p}<0.01)^{\mathrm{a}}$ & $0.674(\mathrm{p}=0.012)^{\mathrm{a}}$ \\
& $5.8 \mathrm{~S}$ rRNA & & & $0.57(\mathrm{p}=0.033)^{\mathrm{a}}$ \\
Tumor & 18 S rRNA & $0.042(\mathrm{p}=0.887)$ & $-0.051(\mathrm{p}=0864)$ & $0.288(\mathrm{p}=0.318)$ \\
& 28S rRNA & & $0.521(\mathrm{p}=0.056)$ & $0.349(\mathrm{p}=0.221)$ \\
& 5.8S rRNA & & & $0.543(\mathrm{p}=0.045)^{\mathrm{a}}$ \\
\hline
\end{tabular}

Significant correlation $\left({ }^{\mathrm{a}} \mathrm{p}<0.05\right)$ was identified using Spearman correlation coefficients $(\mathrm{r})$ and $\mathrm{p}$-values. rRNA, ribosomal RNA; ETS, external transcribed spacer.

rRNA expression levels, as well as relative rRNA proportions in cell lines were found to be independent of their promoter methylation levels (data not shown). These results indicate that rRNA transcripts were expressed even in the presence of heavy methylation at the $45 \mathrm{~S}$ rDNA promoter.

Correlation between $45 S$ rDNA promoter methylation and $18 S$ rRNA expression is disrupted in breast tumors. Next, Spearman's correlation analysis was performed to test whether the 45S rDNA promoter methylation levels in the breast tumor and matched normal samples were correlated with either rRNA expression levels or rRNA proportions in the rRNA pool. When rRNA expression levels were normalized with TBP expression, no correlation between expression and methylation was observed (data not shown). The increase in methylation of the rDNA promoter levels in the normal samples was inversely correlated with the $18 \mathrm{~S}$ rRNA/GM-rRNA expression ratio (Spearman $r=-0.6571$ and $p=0.0128$ ), yet promoter hypermethylation did not exhibit any correlation with $18 \mathrm{~S}$ rRNA/GM-rRNA ratios in the tumor samples (Fig. 8).

Furthermore, $\mathrm{Ct}$ values of rRNAs transcribed from the 45S rDNA promoter were highly correlated with each other in the normal samples, yet this correlation was lost in the tumor samples (Table III).

rRNA expression levels were correlated with the grade of breast cancer. Expression of the 45S ETS region (TBP normal- ization) in tumor samples $(\mathrm{n}=11)$ was positively correlated with the grade of breast cancer (Spearman $r=0.650, p=0.03$ ). Additionally, the 28S/GM-rRNA ratio of tumor samples was also positively correlated (Spearman $\mathrm{r}=0.725, \mathrm{p}=0.012$ ) while the 18S/GM-rRNA ratio was negatively correlated with the grade (Spearman $\mathrm{r}=-0.714, \mathrm{p}=0.014$ ).

\section{Discussion}

A high expression of rRNA transcripts characterizes cancer cells but only a few studies have analyzed the expression of $18 \mathrm{~S}$ rRNA in breast cancer tissues and matched normal samples. Previous studies have mostly focused on testing whether rRNA genes are suitable as reference genes $(26,27)$. One of these studies found that 18S rRNA was expressed at lower levels in breast tumors compared to matched normal tissues in contrast to the general acceptance of higher rRNA expression in tumors (26). None of the studies, however, investigated whether the expression difference between breast cancer and normal pairs was due to rDNA promoter methylation or whether the ratios of spliced products of the $45 \mathrm{~S}$ precursor were differentially expressed between tumor and normal pairs in breast cancer.

DNA methylation is a well-known phenomenon that inactivates transcription by interfering with Pol II binding to the 
promoter (40); since Pol I and Pol II share common features and transcription factors (41-43), DNA methylation in the 45S rDNA promoter may have a similar effect on expression of rRNA genes.

We used both breast cancer cell lines and clinical breast cancer tissues to investigate the methylation levels of rDNA promoters and expression differences of rRNA transcripts, as well as their relationship with each other in breast cancer. We found that breast cancer cell lines were hypermethylated (74-96\% methylation) at the 45S rDNA promoter region (Fig. 2). High methylation levels of rDNA promoters are frequently identified in many transformed cell lines such as Jurkat, CEM, HeLa, KB (44), NIH 3 T3 (45) and HEK293 (46). A genome-wide analysis of aberrant methylation changes with aging in mammals identified the rDNA gene locus in which methylation levels increased age-dependently in both spermatozoa and rat liver cells (47). If the rDNA locus is sensitive to accumulating random methylation over time, the high methylation levels found in breast cancer cell lines may be explained with long-continued culturing, a common characteristic of cancer cell lines.

We could not identify two populations of alleles (one population with a hypermethylated promoter, the other population with a hypomethylated promoter; Fig. 2) in breast cancer cell lines as proposed earlier by other studies (22-25). Considering the repetitive nature of rRNA genes, this result may be due to the low number of clones (5 clones) analyzed for each cell line. Breast cancer cell lines with hypermethylated $45 \mathrm{~S}$ rDNA promoters did not repress or alter the ratio of rRNA transcripts (Fig. 4). rRNA expression levels and proportions of rRNA transcripts were found to be independent of the rDNA promoter methylation levels; this result may indicate that the methylation of the $45 \mathrm{~S}$ rDNA promoter may not be solely responsible for rRNA expression or proportion changes in breast cancer cell lines. Completely methylated (Xenopus leavis sperm DNA) and unmethylated rDNA constructs were found to be transcribed with equal efficiency when transfected to Xenopus leavis oocytes (48). This is consistent with our results in which expression of rRNA transcripts was found to be relatively independent of their rDNA promoter methylation levels.

Upon 5-AZA treatment of breast cancercell lines, expression of some forms of mature rRNA transcripts (significant for 5.8S RNA and 45S ETS) unexpectedly decreased compared to the DMSO-treated group when normalized with TBP (Fig. 5A), while rRNA proportions were not significantly altered within the rRNA pool (Fig. 5B). A recent study demonstrated that the loss of $\mathrm{CpG}$ methylation of the rDNA promoter (either with 5-AZA treatment or DNMT knockout) regions caused cryptic transcription of RNA polymerase II from $45 \mathrm{~S}$ rDNA promoters. Cryptic transcription from rDNA promoters by RNA polymerase II significantly correlates with reduced modification and processing of rRNA transcripts (25). Loss of $\mathrm{CpG}$ methylation at rDNA promoter regions in 5-AZA-treated breast cancer cell lines may be affected by this cryptic RNA polymerase II transcription, which explains the downregulation of $5.8 \mathrm{~S}$ and $45 \mathrm{~S}$ ETS rRNA transcripts in the 5-AZA-treated cell lines. This mechanism, which acts as a negative feedback loop, may be a strategy developed by cells to achieve a balanced expression of rRNA transcripts and prevent energy loss in cells in the absence of $\mathrm{CpG}$ methylation.
Gene expression is usually regulated by a combination of DNA methylation, histone modifications and the activities of chromatin remodeling complexes (49). TSA treatment alone and 5-AZA+TSA treatment did not result in a significant increase in rRNA levels (Fig. 6A), yet the 5.8S rRNA ratio was decreased in the 5-AZA+TSA treated group (Fig. 6B). rRNA transcription may predominantly be regulated by other transcriptional or post-transcriptional mechanisms rather than epigenetic regulatory processes (at least DNA methylation and histone acetylation) in breast cancer cell lines.

The discrepancy between rRNA expression levels (TBP normalization) and rRNA ratios (GM-rRNAs) in the 5-AZAand 5-AZA+TSA-treated groups, compared to their controls, may result from expression changes of TBP upon drug treatment. The change may also be due to some indirect effect of the drugs through other genes as both drugs affect several other genes along with the rDNA genes.

Further analysis of rDNA promoter methylation with the Wilcoxon matched-pairs signed rank test in tissues showed that most of the breast tumors (13/19) had significantly higher methylation levels than their normal counterparts (Fig. 3A). Our findings indicated similarities of methylation patterns within tumors and between tumor and adjacent normal tissues, indicating tissue- and/or locus-specificity of methylation. Methylation analysis of the same region in different tissues and types of cancer may reveal whether the methylation pattern of this region is tissue-specific, cancer-specific or neither, since different tissues display different methylation patterns at different loci (50).

Previous studies have identified rDNA methylation as a prognostic factor in some cancer types $(31,51)$ including breast cancer (30). However, the correlation analysis of methylation levels with clinicopathological characteristics (as described in Table I) of the patients used in the present study did not show any significance (data not shown). Similarly, a breast carcinoma study on 45 paired breast tumor and normal samples could not identify any significant associations between methylation of rDNA promoters, 5' regions of $18 \mathrm{~S}$ and $28 \mathrm{~S}$ rDNA and ER, PR, grade and other clinicopathological features, except nuclear size and grade (32). The use of larger sample sizes may help clarify the clinical importance of rDNA methylation in breast cancer. rRNA transcript expression (45S/TBP and 28S/GM-rRNA) in tumors on the other hand showed a positive correlation with the grade of the tumor. Nuclear pleomorphism is one of the criteria used in the grading of breast cancer, which includes classification of tumors by the size and the shape of the nucleoli (52). An increase in the expression or the ratio of rRNA transcripts may be responsible for the abnormal appearance of nucleoli in higher grade breast cancer samples.

Expression analyses of rRNA transcripts with TBP and GM-rRNA normalizations revealed different sides of the same coin. While the former enables measurement of expression with respect to a stable mRNA pool, use of the latter reflects changes in the relative ratios of rRNA transcript levels. Our data accordingly revealed that $5.8 \mathrm{~S}$ and $45 \mathrm{~S}$ rRNA transcripts were downregulated in the 5-AZA-treated cell lines with TBP normalization (Fig. 5A). However, 5-AZA treatment did not affect rRNA ratios in the cell lines (Fig. 5B). Unlike the cell line results, expression analysis of rRNA genes in the breast tumor and matched normal tissues showed no significant 
difference when normalized with TBP (Fig. 7A) while 18S and 5.8S rRNAs were proportionally altered in the breast tumor tissue samples (Fig. 7B). As stated earlier, the disparity between TBP and GM-rRNA normalizations could be due to the fact that they analyze separate aspects of rRNA expression.

A recent study with results supporting our findings demonstrated that two rRNA forms (5.8S and $45 \mathrm{~S}$ precursors) were overexpressed (TBP normalization) in clinical prostate cancer tissues compared to matched-benign tissues. However, methylation levels of the $45 \mathrm{~S}$ rDNA promoter in the same prostate tumor and normal pairs were not significantly different (24). Another study showed that loss of $\mathrm{CpG}$ methylation at the rDNA promoter surprisingly decrease rRNA transcript levels by disrupting rRNA synthesis and processing via activating cryptic transcription of rRNA genes by Pol II (25).

Different studies have used various reference genes, TBP and ACTB being among the most common, to determine rRNA expression levels in cancer $(23,24,35)$. We used TBP (a RNA polymerase II transcribed gene) to normalize rRNA gene expression and found no significant differences between the breast tumor and matched normal samples. ACTB also failed to identify such differences in our cohort (data not shown). We propose that the geometric mean (GM) of rRNAs synthesized by RNA polymerase I (18S, $5.8 \mathrm{~S}, 28 \mathrm{~S}$ and $45 \mathrm{~S}$ ETS) to normalize rRNA expression can be used to detect relative changes in rRNAs with each other. GM-rRNA may be less prone to changes than Pol II gene transcripts since it is calculated from the rRNA transcripts synthesized by Pol I. When GM-rRNA was used for normalization, 5.8S and 18S rRNA expression levels were significantly upregulated and downregulated, respectively, in the tumor samples compared to the normal pairs (Fig. 7B). Our data indicate that the proportion of $18 \mathrm{~S}$ and $5.8 \mathrm{~S}$ rRNA in the total rRNA pool changed in the opposite direction while total rRNA levels may be relatively constant. We found that methylation levels of normal samples (which exhibit mixed methylation patterns) showed a negative correlation with the 18S rRNA/GM-rRNA expression level but this correlation was disrupted in the tumor samples (Fig. 8). As far as we are aware, this is the first study to show that the methylation status may be reflected in the expression of one or more rRNA transcripts but not all.

Some forms of polycistronic mRNAs and miRNAs that are expressed from the same promoter have been shown to be post-transcriptionally regulated and exist at different levels in plants $(53,54)$. The SNRPN-SNURF gene, possessing a biscistronic structure and sharing a common promoter, for example, is differentially expressed, as identified by both northern blot and microarray analysis in mammalian cells $(55,56)$. As reported in other studies, genes that are expressed from the same promoter can be differentially expressed by other mechanisms apart from the effect of basal transcription machinery.

The maturation of ribosomes is a complex process assisted by multiple factors $(\sim 200)$ that need to be orchestrated in harmony $(57,58)$. Alteration in the methylation levels of rDNA promoters may have an effect on rRNA stabilization, which could leads to this non-proportional change in rRNA transcripts. Moderate levels of rDNA promoter methylation (as observed in normal samples) may still be regulating 18S rRNA levels but this correlation is disrupted in tumor samples, possibly due to the high methylation levels found in the
45S rDNA promoter. Another possibility is that methylation levels can indirectly affect splicing, post-transcriptional modifications and stabilization of rRNA transcripts (25). The fact that normal samples showed a higher correlation between rRNA transcript expression while this correlation was disrupted in tumor samples supported this possibility (Table III), indicating that the methylated promoter of $45 \mathrm{~S}$ rDNA in tumors may have an effect on the processing of rRNAs.

Since rRNA processing and modification are largely dependent on snoRNAs, any change in snoRNA levels globally may be reflected in the rRNA ratios. U50 is a box C/D snoRNA that is required for 2'-O-methylation of two specific positions in the 28S rRNA and was shown to be altered by somatic rearrangements, mutations and deletions in prostate cancer (59), breast carcinoma (60), B-cell lymphoma (61) and colon cancer (62). Another snoRNA, GAS5, was also found to be downregulated in breast cancer (63). Increased methylation levels of rDNA promoters and their effect on rRNA modification and processing need to be better analyzed in future studies.

In conclusion, we found that rRNA transcripts were expressed independently of the hypermethylated 45S rDNA promoter region in breast cancer cell lines. However, the $18 \mathrm{~S}$ rRNA/GM-rRNA ratios were significantly correlated with methylation levels in the normal samples but not in the tumor samples. Promoter methylation of rDNA promoters appears to have a different role than regulating the expression of rRNA transcripts in breast cancer. It may be used as a mechanism to stabilize and protect these essential genes under any circumstances. rDNA repeats have been proposed to be responsible for genomic stability (64) and hypomethylation of rDNA promoter has been implicated in decreased genomic stability $(65,66)$. Increased methylation of the rDNA promoter in tumor cells may be an indicator of the tumor cell effort to restore impaired genomic stability. Future research is needed to evaluate the cause of relative expression changes observed among rRNA transcripts in tumors and their relationship with rDNA promoter methylation.

\section{Acknowledgements}

The present study was supported by the Scientific and Technical Research Council of Turkey (TUBITAK) (grant no. TBAG-107T181). We thank Dr Daniel Press for the English editing of the manuscript.

\section{References}

1. Ferlay J, Soerjomataram I, Ervik M, Dikshit R, Eser S, Mathers C, Rebelo M, Parkin DM, Forman D and Bray F: GLOBOCAN 2012 v1.0, Cancer Incidence and Mortality Worldwide: IARC CancerBase No. 11. http://globocan.iarc.fr. 2013.

2. Lalloo F and Evans DG: Familial breast cancer. Clin Genet 82: 105-114, 2012.

3. Jaenisch R and Bird A: Epigenetic regulation of gene expression: How the genome integrates intrinsic and environmental signals. Nat Genet 33 (Suppl): S245-S254, 2003.

4. Salozhin SV, Prokhorchuk EB and Georgiev GP: Methylation of DNA - one of the major epigenetic markers. Biochemistry 70 : 525-532, 2005.

5. Nafee TM, Farrell WE, Carroll WD, Fryer AA and Ismail KM: Epigenetic control of fetal gene expression. BJOG 115: 158-168, 2008.

6. Esteller M: Aberrant DNA methylation as a cancer-inducing mechanism. Annu Rev Pharmacol Toxicol 45: 629-656, 2005. 
7. Karpinets TV and Foy BD: Tumorigenesis: The adaptation of mammalian cells to sustained stress environment by epigenetic alterations and succeeding matched mutations. Carcinogenesis 26: 1323-1334, 2005.

8. Baylin SB and Ohm JE: Epigenetic gene silencing in cancer a mechanism for early oncogenic pathway addiction? Nat Rev Cancer 6: 107-116, 2006.

9. Dez C and Tollervey D: Ribosome synthesis meets the cell cycle. Curr Opin Microbiol 7: 631-637, 2004.

10. McKnight SL and Miller OL Jr: Ultrastructural patterns of RNA synthesis during early embryogenesis of Drosophila melanogaster. Cell 8: 305-319, 1976.

11. Schmickel RD: Quantitation of human ribosomal DNA: Hybridization of human DNA with ribosomal RNA for quantitation and fractionation. Pediatr Res 7: 5-12, 1973.

12. Warner JR: The economics of ribosome biosynthesis in yeast. Trends Biochem Sci 24: 437-440, 1999.

13. Russell J and Zomerdijk JC: RNA-polymerase-I-directed rDNA transcription, life and works. Trends Biochem Sci 30: 87-96, 2005.

14. Paule MR and White RJ: Survey and summary: Transcription by RNA polymerases I and III. Nucleic Acids Res 28: 1283-1298, 2000.

15. Learned RM, Learned TK, Haltiner MM and Tjian RT: Human rRNA transcription is modulated by the coordinate binding of two factors to an upstream control element. Cell 45: 847-857, 1986.

16. Clos J, Buttgereit D and Grummt I: A purified transcription factor (TIF-IB) binds to essential sequences of the mouse rDNA promoter. Proc Natl Acad Sci USA 83: 604-608, 1986.

17. Eichler DC and Craig N: Processing of eukaryotic ribosomal RNA. Prog Nucleic Acid Res Mol Biol 49: 197-239, 1994.

18. Trapman J, Retèl J and Planta RJ: Ribosomal precursor particles from yeast. Exp Cell Res 90: 95-104, 1975.

19. Venema J and Tollervey D: Ribosome synthesis in Saccharomyces cerevisiae. Annu Rev Genet 33: 261-311, 1999.

20. Esteller M: Epigenetic gene silencing in cancer: The DNA hypermethylome. Hum Mol Genet 16: R50-R59, 2007.

21. Worton RG, Sutherland J, Sylvester JE, Willard HF, Bodrug S, Dubé I, Duff C, Kean V, Ray PN and Schmickel RD: Human ribosomal RNA genes: Orientation of the tandem array and conservation of the 5' end. Science 239: 64-68, 1988.

22. Ghoshal K, Majumder S, Datta J, Motiwala T, Bai S, Sharma SM, Frankel W and Jacob ST: Role of human ribosomal RNA (rRNA) promoter methylation and of methyl-CpG-binding protein MBD2 in the suppression of rRNA gene expression. J Biol Chem 279: 6783-6793, 2004.

23. Raval A, Sridhar KJ, Patel S, Turnbull BB, Greenberg PL and Mitchell BS: Reduced rRNA expression and increased rDNA promoter methylation in $\mathrm{CD} 34^{+}$cells of patients with myelodysplastic syndromes. Blood 120: 4812-4818, 2012.

24. Uemura M, Zheng Q, Koh CM, Nelson WG, Yegnasubramanian S and De Marzo AM: Overexpression of ribosomal RNA in prostate cancer is common but not linked to rDNA promoter hypomethylation. Oncogene 31: 1254-1263, 2012.

25. Gagnon-Kugler T, Langlois F, Stefanovsky V, Lessard F and Moss T: Loss of human ribosomal gene $\mathrm{CpG}$ methylation enhances cryptic RNA polymerase II transcription and disrupts ribosomal RNA processing. Mol Cell 35: 414-425, 2009.

26. Gur-Dedeoglu B, Konu O, Bozkurt B, Ergul G, Seckin S and Yulug IG: Identification of endogenous reference genes for qRT-PCR analysis in normal matched breast tumor tissues. Oncol Res 17: 353-365, 2009.

27. Tricarico C, Pinzani P, Bianchi S, Paglierani M, Distante V, Pazzagli M, Bustin SA and Orlando C: Quantitative real-time reverse transcription polymerase chain reaction: Normalization to rRNA or single housekeeping genes is inappropriate for human tissue biopsies. Anal Biochem 309: 293-300, 2002.

28. de Kok JB, Roelofs RW, Giesendorf BA, Pennings JL, Waas ET, Feuth T, Swinkels DW and Span PN: Normalization of gene expression measurements in tumor tissues: Comparison of 13 endogenous control genes. Lab Invest 85: 154-159, 2005.

29. Chan MW, Wei SH, Wen P, Wang Z, Matei DE, Liu JC, Liyanarachchi S, Brown R, Nephew KP, Yan PS, et al: Hypermethylation of $18 \mathrm{~S}$ and $28 \mathrm{~S}$ ribosomal DNAs predicts progression-free survival in patients with ovarian cancer. Clin Cancer Res 11: 7376-7383, 2005.
30. Yan PS, Rodriguez FJ, Laux DE, Perry MR, Standiford SB and Huang TH: Hypermethylation of ribosomal DNA in human breast carcinoma. Br J Cancer 82: 514-517, 2000.

31. Powell MA, Mutch DG, Rader JS, Herzog TJ, Huang TH and Goodfellow PJ: Ribosomal DNA methylation in patients with endometrial carcinoma: An independent prognostic marker. Cancer 94: 2941-2952, 2002.

32. Bacalini MG, Pacilli A, Giuliani C, Penzo M, Treré D, Pirazzini C, Salvioli S, Franceschi C, Montanaro L and Garagnani P: The nucleolar size is associated to the methylation status of ribosomal DNA in breast carcinomas. BMC Cancer 14: 361, 2014.

33. Kumaki Y, Oda M and Okano M: QUMA: Quantification tool for methylation analysis. Nucleic Acids Res 36: W170-W175, 2008.

34. Haltiner MM, Smale ST and Tjian R: Two distinct promoter elements in the human rRNA gene identified by linker scanning mutagenesis. Mol Cell Biol 6: 227-235, 1986.

35. Brown SE and Szyf M: Dynamic epigenetic states of ribosomal RNA promoters during the cell cycle. Cell Cycle 7: 382-390, 2008.

36. Guo C, Liu S, Wang J, Sun MZ and Greenaway FT: ACTB in cancer. Clin Chim Acta 417: 39-44, 2013.

37. Guo C, Liu S and Sun MZ: Novel insight into the role of GAPDH playing in tumor. Clin Transl Oncol 15: 167-172, 2013.

38. Esteller M, Corn PG, Baylin SB and Herman JG: A gene hypermethylation profile of human cancer. Cancer Res 61: 3225-3229, 2001 .

39. Ballestar E and Esteller M: Epigenetic gene regulation in cancer. Adv Genet 61: 247-267, 2008.

40. Eden $\mathrm{S}$ and Cedar H: Role of DNA methylation in the regulation of transcription. Curr Opin Genet Dev 4: 255-259, 1994.

41. Sentenac A: Eukaryotic RNA polymerases. CRC Crit Rev Biochem 18: 31-90, 1985.

42. Sharp PA: TATA-binding protein is a classless factor. Cell 68: 819-821, 1992.

43. Comai L, Tanese $\mathrm{N}$ and Tjian R: The TATA-binding protein and associated factors are integral components of the RNA polymerase I transcription factor, SL1. Cell 68: 965-976, 1992.

44. Kochanek S, Hosokawa K, Schiedner G, Renz D and Doerfler W: DNA methylation in the promoter of ribosomal RNA genes in human cells as determined by genomic sequencing. FEBS Lett 388: 192-194, 1996.

45. Németh A, Guibert S, Tiwari VK, Ohlsson R and Längst G: Epigenetic regulation of TTF-I-mediated promoter-terminator interactions of rRNA genes. EMBO J 27: 1255-1265, 2008.

46. Brown SE and Szyf M: Epigenetic programming of the rRNA promoter by MBD3. Mol Cell Biol 27: 4938-4952, 2007.

47. Oakes CC, Smiraglia DJ, Plass C, Trasler JM and Robaire B: Aging results in hypermethylation of ribosomal DNA in sperm and liver of male rats. Proc Natl Acad Sci USA 100: 1775-1780, 2003.

48. Macleod D and Bird A: Transcription in oocytes of highly methylated rDNA from Xenopus laevis sperm. Nature 306: 200-203, 1983.

49. Richards EJ and Elgin SC: Epigenetic codes for heterochromatin formation and silencing: Rounding up the usual suspects. Cell 108: 489-500, 2002.

50. Muangsub T, Samsuwan J, Tongyoo P, Kitkumthorn N and Mutirangura A: Analysis of methylation microarray for tissue specific detection. Gene 553: 31-41, 2014.

51. Chan MW, Wei SH, Wen P, Wang Z, Matei DE, Liu JC, Liyanarachchi S, Brown R, Nephew KP, Yan PS, et al: Hypermethylation of $18 \mathrm{~S}$ and $28 \mathrm{~S}$ ribosomal DNAs predicts progression-free survival in patients with ovarian cancer. Clin Cancer Res 11: 7376-7383, 2005.

52. Egner JR: AJCC Cancer Staging Manual. JAMA J Am Med Assoc 304: 1726, 2010.

53. Jia F and Rock CD: MIR846 and MIR842 comprise a cistronic MIRNA pair that is regulated by abscisic acid by alternative splicing in roots of Arabidopsis. Plant Mol Biol 81: 447-460, 2013.

54. Malik Ghulam M, Courtois F, Lerbs-Mache S and Merendino L: Complex processing patterns of mRNAs of the large ATP synthase operon in Arabidopsis chloroplasts. PLoS One 8: e78265, 2013.

55. Li SS, Yu SL and Singh S: Epigenetic states and expression of imprinted genes in human embryonic stem cells. World J Stem Cells 2: 97-102, 2010.

56. Gray TA, Saitoh S and Nicholls RD: An imprinted, mammalian bicistronic transcript encodes two independent proteins. Proc Natl Acad Sci USA 96: 5616-5621, 1999. 
57. Kiss T, Fayet E, Jády BE, Richard $P$ and Weber M: Biogenesis and intranuclear trafficking of human box C/D and H/ACA RNPs. Cold Spring Harb Symp Quant Biol 71: 407-417, 2006.

58. Terns $M$ and Terns R: Noncoding RNAs of the H/ACA family. Cold Spring Harb Symp Quant Biol 71: 395-405, 2006.

59. Dong XY, Rodriguez C, Guo P, Sun X, Talbot JT, Zhou W, Petros J, Li Q, Vessella RL, Kibel AS, et al: SnoRNA U50 is a candidate tumor-suppressor gene at $6 \mathrm{q} 14.3$ with a mutation associated with clinically significant prostate cancer. Hum Mol Genet 17: 1031-1042, 2008.

60. Dong XY, Guo P, Boyd J, Sun X, Li Q, Zhou W and Dong JT: Implication of snoRNA U50 in human breast cancer. J Genet Genomics 36: 447-454, 2009.

61. Tanaka R, Satoh H, Moriyama M, Satoh K, Morishita Y, Yoshida S, Watanabe T, Nakamura Y and Mori S: Intronic U50 small-nucleolar-RNA (snoRNA) host gene of no proteincoding potential is mapped at the chromosome breakpoint $t(3 ; 6)$ (q27;q15) of human B-cell lymphoma. Genes Cells 5: 277-287, 2000 .
62. Pacilli A, Ceccarelli C, Treré D and Montanaro L: SnoRNA U50 levels are regulated by cell proliferation and rRNA transcription. Int J Mol Sci 14: 14923-14935, 2013.

63. Mourtada-Maarabouni M, Pickard MR, Hedge VL, Farzaneh F and Williams GT: GAS5, a non-protein-coding RNA, controls apoptosis and is downregulated in breast cancer. Oncogene 28: 195-208, 2009

64. Kobayashi T: Ribosomal RNA gene repeats, their stability and cellular senescence. Proc Jpn Acad Ser B Phys Biol Sci 90: 119-129, 2014.

65. Peng JC and Karpen GH: H3K9 methylation and RNA interference regulate nucleolar organization and repeated DNA stability. Nat Cell Biol 9: 25-35, 2007.

66. Kobayashi T: A new role of the rDNA and nucleolus in the nucleus - rDNA instability maintains genome integrity. Bioessays 30: 267-272, 2008 . 